\title{
(Des-)construindo o gesto do violonista em quatro obras da segunda metade do século XX
}

\section{Title: Deconstructing the guitarist's gesture: the relationship with the instrument according to three twentieth-century composers}

\author{
(iD) Ledice Fernandes Weiss ${ }^{1}$ \\ email: ledicef@hotmail.com
}

Resumo: Visando a compreender a relação entre performance instrumental e escrita, apresentamos uma perspectiva analítica musical baseada no gesto. Contemplamos o enriquecimento gestual do violonista em perspectivas teatralizantes (movimentação cênica, ações instrumentais inovadas, busca de novas sonoridades...). Incorporamos conceitos como o de desconstruir o gesto instrumental, presente na musique concrète instrumentale de Helmut Lachenmann (Salut für Caudwell) e na Tapping Technique de Arthur Kampela (Percussion Study I). Integramos as relações lúdicas que se criam entre os performers e o instrumento no teatro instrumental de Mauricio Kagel (Sonant e Serenade). As perspectivas se ampliam ao constatarmos a criação de novas ações instrumentais, que incluem o uso de acessórios no jogo instrumental e a dissociação gestual das mãos.

Palavras-chave: Performance musical. Gesto instrumental. Mauricio Kagel. Helmut Lachenmann. Arthur Kampela.

\footnotetext{
1 Ledice Fernandes é pós-doutorando financiada pela FAPESP na ECA-USP, trabalhando com a noção do gesto (instrumental, sonoro, corporal e cênico) na performance musical. Formada em violão no Brasil, seu país natal, na Alemanha e na França, com Pablo Marquez, Paul Galbraith, Franz Halasz e David Russell. Em seu percurso, obteve diplomas como o Künstlerisches Diplom e o Meisterklasse da Hochschule für Musik Nürnberg-Augsburg. Deu mais de uma centena de concertos, como solista ou em formações de música de câmara, como o recente Duo Racines com Angelique Camargo, ou o grupo de música cênica Anagrama. Ledice Fernandes participou de projetos teatrais tanto no Brasil como durante sua estadia nos Estados Unidos na Georgia State University. Após ter se graduado bacharel em artes cênicas pela USP e mestre em música e musicologia pela UFRJ, produziu um Master II e uma tese de doutorado na França (Universidades de Lyon e de Bourgogne). Participou de congressos (ANPPOM - onde coordena em 2019 pela segunda vez consecutiva um Simpósio Temático-, ABRAPEM, Journées d'etudes em Nice, EITAM), e publicou artigos em revistas de música (Opus, Debates, Vortex, Soundboard, Violão Intercâmbio).
} 


\begin{abstract}
In order to understand the relationship between instrumental performance and musical writing, we present an analytical approach based on the gesture. We admit the instrumental enrichment of the guitar performer in theatrical perspectives (Scenic Movement, innovative instrumental actions, the search for new sounds...). We incorporate concepts such as that of deconstructing the instrumental gesture, present in Helmut Lachenmann's musique concrète instrumentale (Salut für Caudwell) and in the Tapping Technique of Arthur Kampela (Percussion Study I). We integrate the playful relationships between the performers and the instrument in the Instrumental Theater of Mauricio Kagel (Sonant and Serenade). The perspectives are broadened by the creation of new instrumental actions, which include the use of accessories and the dissociation of hands.
\end{abstract}

Keywords: Musical Performance. Instrumental Gesture. Mauricio Kagel. Helmut Lachenmann. Arthur Kampela.

Submetido em 14 de abril de 2020

Aprovado em: 17 de julho de 2020 


\title{
I. A análise musical do ponto de vista da performance
}

\author{
"É o gesto que produz o som e não o instrumento musical" \\ (STOIANOVA, 1978:10).
}

A questão da relação entre performance instrumental e escrita tornou-se, desde a metade do século XX, uma das bases da composição musical. A escrita musical tentando incorporar cada vez mais componentes que não são sonoros (o gesto do instrumentista, a movimentação no palco, elementos de encenação, a relação ao espaço) e que nascem, muitas vezes, na própria performance (ou, ao menos, a visam diretamente). $O$ desenvolvimento de tal relação foi possível, por um lado, graças ao questionamento acerca do que seria, de fato, a composição e a escrita musicais, a partir do momento em que nem uma nem outra pareceram se restringir ao paradigma da partitura: tanto a escrita como a composição podem criar-se em experiências performáticas ou dentro da colaboração entre intérpretes e compositores (FERNANDES WEISS, 2019a). Por outro lado, os questionamentos acerca da escrita aconteceram em paralelo ao desenvolvimento de tendências e estéticas completamente divergentes entre si (como o teatro musical, a música improvisada, a prática de instrumentos antigos....), mas que convergiam no sentido de considerá-la (a escrita) um processo dinâmico em simbiose com a prática musical, sobretudo relacionado a um pensamento gestual da música.

O objetivo do presente estudo é abordar a análise musical do ponto de vista da performance. Para tanto, nos debruçaremos sobre o gesto instrumental, que é visto ao mesmo tempo como agente de exploração timbrística e como gerador de signos cênicos e coreográficos, tomando como exemplo o caso do violão em algumas obras do século XX.

Abordaremos, para tanto, o ponto de vista de três compositores diferentes que, cada um à sua maneira, se ocuparam dessa questão: Mauricio Kagel (1931-2008), com seu teatro instrumental, 
(Des-)construindo o gesto do violonista em quatro obras da segunda metade do século XX Ledice Fernandes Weiss

que terá em Sonant e em Serenade, obras de 1960 e 1994, um exemplo pioneiro e um tardio; Helmut Lachenmann (1935) e a musique concrète instrumentale, que será exemplificada em sua obra de 1977, Salut für Caudwell, e Arthur Kampela (1960), com sua tapping technique, exemplificada por sua Percussion Study I de 1990.

Nesse repertório, há um denominador comum, que é o desejo de se abordar o instrumento a partir de novos gestos instrumentais. Trata-se de investigar na própria concepção do instrumento as diversas possibilidades de relação entre o gesto instrumental e o som resultante. Tal investigação traz como como resultado alguns aspectos importantes:

1. A composição valoriza a gestualidade instrumental, isto é, a relação física do instrumentista com o instrumento, sobretudo através da exploração de novos meios técnicos.

- Por consequência, não se esconde mais a técnica, mas a revela. A ferramenta técnica não é mais somente um meio, mas também um fim, e vira elemento cênico.

- Essa relação física traz à tona, revela e deflagra o esforço físico exigido do instrumentista para tocar seu instrumento. $O$ fato de se mostrarem enquanto ingredientes deliberados da composição, enquanto elementos cênicos e objetos artísticos; a própria técnica, o esforço, o gesto e o movimento que geram os sons instrumentais se assemelham a procedimentos caros ao teatro moderno, de "ruptura" da quarta parede, do despertar do público para os "bastidores" da ilusão teatral, de questionamento da tecnicidade que está por trás de um objeto artístico acabado, de distanciamento no sentido brechtiano e, enfim, de uma arte que "discursa" sobre ela mesma. Com uma espécie de auto-referenciamento que beira a metalinguagem, não ousando todavia roubar para si questionamentos estéticos que pertencem tipicamente a domínios semiológicos, essa valorização do gesto instrumental traz consigo um questionamento ontológico sobre o fazer artístico. 
(Des-)construindo o gesto do violonista em quatro obras da segunda metade do século XX Ledice Fernandes Weiss

2. Ao valorizar o gesto instrumental, a composição incentiva ao mesmo tempo a exploração do espaço físico do instrumento e do espaço ao redor do instrumentista. Há uma maior conscientização do performer com relação à sua ocupação espacial, que se dá por meio da projeção do som, da movimentação dos membros em relação ao instrumento e dos deslocamentos de seu corpo em infinitas propostas que rompem com a natureza estática, outrora característica de um violonista sentado em sua cadeira (preparação instrumental, mudança de instrumento, mudança de posição no palco, execução de ações fora do instrumento...). Além disso, a questão espacial dialoga com a notação não convencional que muitas vezes estas partituras adotam na espacialização da superfície da partitura e na notação dos gestos com relação ao espaço físico do instrumento. Em alguns casos, portanto, a notação não indica propriamente 0 que soa, mas onde e como agir no instrumento por meio de símbolos e textos ${ }^{2}$. Este estudo específico da espacialização dos movimentos do performer, reservamos para um futuro artigo, em que dedicamos um grande espaço à questão da percepção geométrica da ocupação do corpo no espaço.

3. A relação entre instrumentista e instrumento se tornando mais física, o "discurso musical" é orientado por um pensamento mais gestual e menos linear ou racional. Ao invés de construir uma estrutura a partir de sistemas musicais, a composição se vale de elementos táteis e visuais, além de sonoros. O contato com o instrumento se reveste de uma qualidade cinética e a técnica instrumental se torna reinventando os ensinamentos do grande homem de teatro polonês Jerzy Grotowski (1933-1999) - um conjunto de "ações" instrumentais.

4. Ao ampliar o repertório potencial de gestos instrumentais, incorporando outras fontes sonoras e acessórios

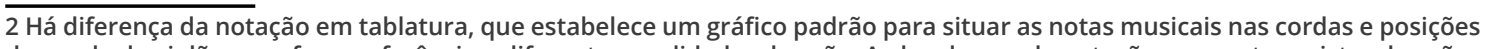
da escala do violão, sem fazer referência a diferentes qualidades de ação. A abordagem da notação enquanto registro de ações no instrumento é, no entanto, semelhante. 
(Des-)construindo o gesto do violonista em quatro obras da segunda metade do século XX Ledice Fernandes Weiss

instrumentais, também se amplia o repertório de sons produzidos.

\section{Apologia do gesto}

Nossa proposta analítica é, portanto, a de se entender o fenômeno musical sob o prisma do gesto, cuja noção é associada à de movimento, ação³, intenção, atuação e corporificação (do inglês, embodiment), noção esta que significaria o próprio esquema mental do movimento (GODOY, LEMAN, 2010, p. 8). Este enfoque se adequa àquele que atribui à música um aspecto visual particularmente relevante, advindo dos gestos e movimentos dos intérpretes, entre eles e em relação ao público (DEMOZ, 2017, p. 14). Há, em um projeto analítico como este, uma profunda mudança de paradigma, transferindo o foco dos "símbolos mais abstratos da notação musical para a experiência holística de som e movimento contínuos em relação a nossos corpos" (GODOY, LEMAN, 2010, p. ix).

Enxergamos nesta mudança de paradigma uma aproximação com o projeto teatral de Grotowski (1971, p.16-17), em que se intenta eliminar gradualmente tudo o que seria supérfluo ao teatro (maquiagem, figurino, cenografia, palco, efeitos sonoros e luminosos), foca-se no relacionamento de comunhão entre o ator e o espectador, reduzindo o fenômeno artístico ao essencial, o corpo do ator-músico. Outro parentesco se encontra na concepção musical do alemão Dieter Schnebel (1930-2018), também focado no corpo do intérprete, "cujos gestos, minuciosamente notados e trabalhados como escalas musicais, se tornam a fonte da música" (DEMOZ, 2017, p. 14)

Compositores como Mauricio Kagel e Arthur Kampela, mas também Silvano Bussotti, Karlheinz Stockhausen, John Cage e particularmente Dieter Schnebel, que quis metodicamente escrever música a partir de elementos visíveis (DEMOZ, 2017, p. 7), sublinharam justamente seu aspecto teatral e trouxeram um questionamento primordial, que é o da necessidade de se aprofundarem nas formas de registro do gesto. Este último, por fim, desemboca

\footnotetext{
3 Rodrigues (2012, p. 20) introduz o termo "ação musical" em analogia à ideia de ação física segundo Stanislavski e Grotowski.
} 
(Des-)construindo o gesto do violonista em quatro obras da segunda metade do século XX Ledice Fernandes Weiss

no problema de se considerar o trabalho do performer enquanto instância criativa, sendo ele um parceiro do compositor na própria criação musical.

\section{A performance enquanto instância criativa}

Ainda que as obras que analisamos aqui tenham se fixado na forma escrita, a partitura não é o verdadeiro modelo criativo com que estamos lidando, uma vez que, nos quatro exemplos, a escrita parte da experiência prática em performance (seja por meio de roteiros de ações em Kagel, seja nas experimentações do compositor-violonista em Kampela, seja na investigação da materialidade do instrumento em Lachenmann). Consequentemente, o ato performático dessas obras não se restringe a reproduzir o que é dado pela partitura, mas pode ter a autonomia de re-criar o gesto corporal que esteve em sua origem. A dimensão criativa da performance é vinculada à física, como salienta Rodrigues (2012, p. 72) quando afirma que "tocar um instrumento é um tipo de ação física do músico. Como para o ator, é o estudo meticuloso dessas pequenas ações e sua performance que criam as condições para que uma determinada emoção possa surgir".

Reivindicamos, como o fez Grotowski (1971, p. 36), que o elemento que distingue as artes performáticas das demais é justamente a "proximidade do organismo vivo" que traz consigo seus "gestos mágicos", únicos. Reconhecemos, em seguida, que a essência dessas formas artísticas efêmeras não está, justamente, no que foi dado de fora ao performer, por exemplo, sob uma forma escrita: "não está nem na narração, nem no acontecimento, nem na discussão de uma hipótese com a platéia, nem na representação da vida que aparece exteriormente", mas acontece no aqui e agora (Ibid, p. 93). Assim, faz-se necessário que o papel do performer seja visto em sua dimensão vital e criativa. Esta é a abordagem que se quer dar à análise musical de quatro obras do fim do século XX: aquela em que o performer des-constrói seu gesto, ingrediente 
(Des-)construindo o gesto do violonista em quatro obras da segunda metade do século XX Ledice Fernandes Weiss

primeiro da criação musical, atualizando ao mesmo tempo escrita e performance.

\title{
IV. A desconstrução do gesto
}

Levando esse conjunto de problemáticas a uma reflexão aprofundada, dois compositores de vivências musicais distintas apresentaram, curiosamente, soluções similares, inclusive em suas formulações: Helmut Lachenmann e Arthur Kampela nos propõem a desconstrução do gesto instrumental. Para nosso estudo, esta pode ser vista como uma valiosa maneira de se "reinventar" a técnica do violão, e um ponto crucial da escrita contemporânea, claramente presente nas obras que percorreremos adiante. A desconstrução do gesto, assim como sua (re-)construção, seria então um ponto de interseção entre a escrita e a performance, o lugar onde as duas funções (compor, interpretar) convergem.

As inovações técnicas que Lachenmann traz à sua música instrumental desde o fim dos anos 1960, que brotam e re-brotam de um insaciável processo de desconstrução e reconstrução, são uma consequência direta de sua "música concreta instrumental"4. Com ela, o compositor almejava « reconstruir » os próprios instrumentos musicais e os gestos que a eles são associados, a fim de dar aos primeiros novas possibilidades de produção sonora, e de reinventar expressivamente os processos mecânicos dos segundos.

\begin{abstract}
Trata-se do som visto como resultado característico e signo de sua produção mecânica e da energia utilizada nesse momento, com maior ou menor economia [...]. Por minha parte, eu quero profanar o som, o des- musicalisar apresentando-o como o resultado direto ou indireto de ações e processos mecânicos, a fim de lançar as bases para uma nova compreensão (LACHENMANN, 2002, p. 45-46).
\end{abstract}

$4 \mathrm{O}$ conceito de musique concrète instrumentale criado por Lachenmann no fim dos anos 1960 busca revelar a energia e a resistência com que o som é produzido nos instrumentos tradicionais (LACHENMANN, 2002, p. 45). 
(Des-)construindo o gesto do violonista em quatro obras da segunda metade do século XX Ledice Fernandes Weiss

É dessa forma que a "música concreta instrumental" pretende desmascarar o processo de produção de som, o esforço e a energia fornecidos pelo instrumentista. Graças a essa preocupação com as ações instrumentais, a estética de Lachenmann se aproxima das ambições expressivas do "teatro instrumental" de Mauricio Kagel, igualmente focado na ideia de expressar o processo técnico, físico e mecânico de produção de som. Os procedimentos de Lachenmann promovem uma renovação na maneira de se tocar o instrumento, ultrapassando as práticas padronizadas e permitindo que a energia empregada se torne o cerne da composição, mais do que o próprio instrumento.

\begin{abstract}
A ação instrumental serve sem dúvida uma idéia sonora precisamente escrita, mas não desaparece por trás dela; o resultado sonoro quer, em vez disso, chamar a atenção, através de uma corporeidade particular, sobre o gesto por trás dele, fazendo-nos tornarmo-nos conscientes das condições mecânicas, energéticas, que produziram este resultado (LACHENMANN, 2002, p. 54).
\end{abstract}

Lachenmann desejava, com sua musique concrète instrumentale, questionar as convenções musicais e nossos hábitos de escuta, propondo uma reflexão original sobre a natureza do som. Sua proposta, podendo ser considerada "negativa" e "destrutiva", visava a eliminar aquilo que era senso comum, considerado "belo", e "aniquilar o substrato histórico de material sonoro" (HILBERG, 1995, p. 27). Desprovido de sua técnica tradicional, de seu patrimônio histórico e cultural, o instrumento se torna um objeto ou utensílio (Gerät), que "manipulamos" (hantieren), que "tocamos" (abtasten), que exploramos pelo tato, e que exige portanto do instrumentista uma nova maneira de abordá-lo.

O devir-utensílio do instrumento é um ponto central para a estética de Lachenmann e um dos catalisadores constantes de sua imaginação sonora; ele chega a falar dos instrumentos como 
(Des-)construindo o gesto do violonista em quatro obras da segunda metade do século XX Ledice Fernandes Weiss

móveis a se desmontarem e remontarem, posto que eles representam, para ele, uma 'mobília cultural' (KALTENECKER, 2002, p. $67)$.

A partir disso, Lachenmann emprega técnicas instrumentais e vocais desterritorializadas, fragmentando o texto em sílabas e fonemas, e criando uma grande variedade de cores instrumentais, sendo a sonoridade "abafada" (erstickt) uma das que mais instigaram-no, como veremos em Salut für Caudwell.

Por sua vez, Arthur Kampela se propõe, segundo suas próprias palavras, a repensar o instrumento-violão e o músico-violonista, com o objetivo de os "desconstruir". Como Lachenmann, Kampela de certa forma "rejeita" a técnica tradicional e almeja integrar os "ruídos" que produz o instrumento musical. Ele também propõe uma reflexão sobre nossos hábitos de escuta:

Quando você faz algo incomum no instrumento, pode ser estranho, mas se isso é integrado na maneira de tocar, isso pode se tornar uma forma interessante de reinvestir o instrumento, de maneira que começamos a entender os gestos das mãos. Eu gosto de desconstruir todos os instrumentos com os quais lido. A ideia de desconstrução do instrumento [...] é de entender que o instrumento tem um contexto histórico, e que sua morfologia, a forma como é construído, induzem a uma determinada maneira de tocar. No entanto, existem muitas outras maneiras de tocá-lo, contido em sua própria constituição, o que faz com que todos os instrumentos tornem-se instrumentos de percussão (KAMPELA, 2005).

Vale observar que a obra instrumental inteira de Mauricio Kagel também é caracterizada pela integração do ruído e de sons "aspirados", sons que fascinaram igualmente Lachenmann, que, por sua vez, também se concentra em negar o conceito do "som belo" clássico. 
(Des-)construindo o gesto do violonista em quatro obras da segunda metade do século XX Ledice Fernandes Weiss

\section{O teatro instrumental de Mauricio Kagel}

Mauricio Kagel inventa, a partir de uma obra de 1960, Sur scène, o gênero do "teatro instrumental", um gênero cuja teatralidade se calca na própria situação de concerto e nos gestos e reações dos instrumentistas em cena. No teatro instrumental, o "conflito" é muitas vezes estabelecido entre o músico e seu instrumento, ou dos músicos entre si. São teatralizados mesmo os problemas puramente técnicos e musicais, o que faz com que a música adquira uma essência teatral, nascendo quase espontaneamente da simples presença, da interação, dos movimentos, gestos, ações e jogos cênicos criados entre os músicos.

Há pontos comuns evidentes entre o teatro instrumental de Kagel e a musique concrète instrumentale de Lachenmann, particularmente no querer tornar expressivo o processo técnico, físico e mecânico de produção do som. No entanto, deve-se observar que, enquanto essa busca é para Kagel muitas vezes associada ao humor, a uma estética surrealista e próxima ao teatro do absurdo, em Lachenmann o aspecto lúdico é deliberadamente negado.

\section{V.1 Sonant (1960) de Mauricio Kagel}

Sonant é a segunda obra de «théâtre instrumental» que Mauricio Kagel compôs. Escrita para quatro músicos (violão e guitarra, harpa, baixo, percussão), a partitura alterna partes em que uma sequência temporal é estabelecida por pautas, contendo notação musical tradicional, indicações gráficas e recomendações por escrito, e outras que se assemelham a roteiros onde se propõem, por escrito, situações cênicas às quais os intérpretes devem reagir espontaneamente. Alguns símbolos que aparecem na partitura são explicados na bula (exemplo 1) e indicam ações musicais de grande potencial lúdico ("tocar notas em qualquer ordem", "grande atividade", "improvisar com diferentes formas de ataque"). 
(Des-)construindo o gesto do violonista em quatro obras da segunda metade do século XX Ledice Fernandes Weiss

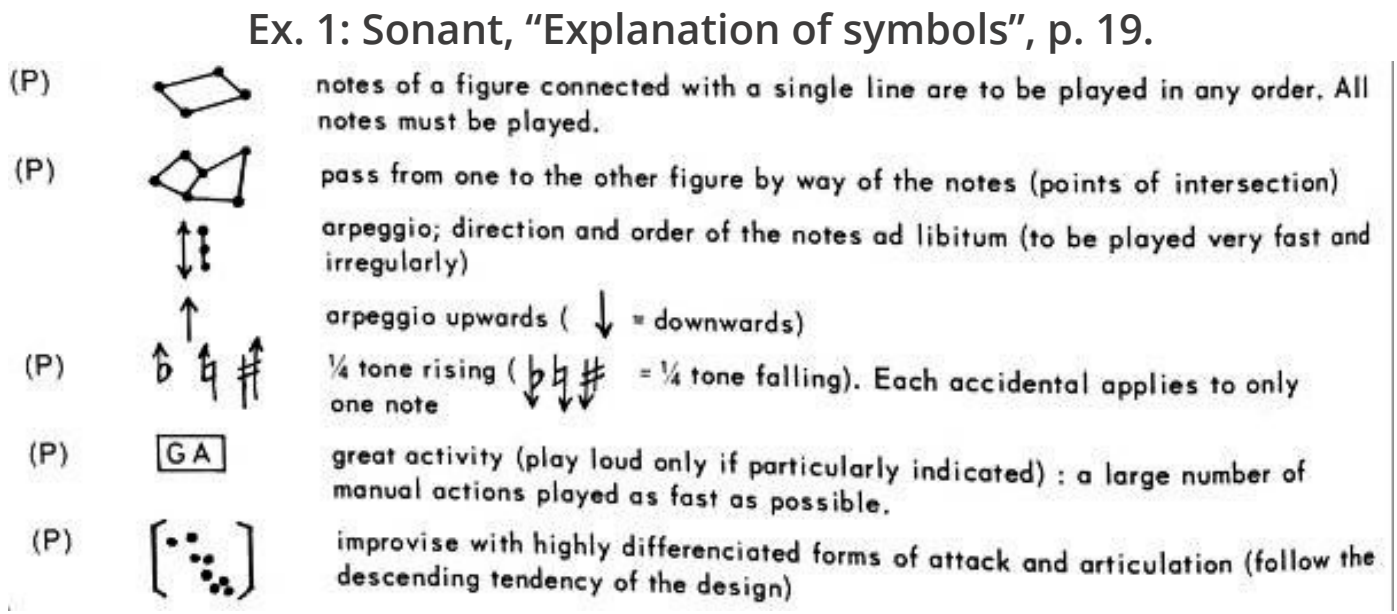

Como em uma obra posterior e emblemática, Staatstheater, alguns dos movimentos de Sonant não possuem grade: cada intérprete recebe uma parte separada, em que são dados vários estímulos visuais que devem ser interpretados e articulados individualmente. O resultado sonoro de Sonant é praticamente sempre imprevisível, mesmo no caso mais tradicional de passagens como a do exemplo 2, em que vemos uma pauta musical e alturas de notas sugeridas.

Ex. 2: Sonant, Faites votre jeu II, parte de guitarra, p. 1.

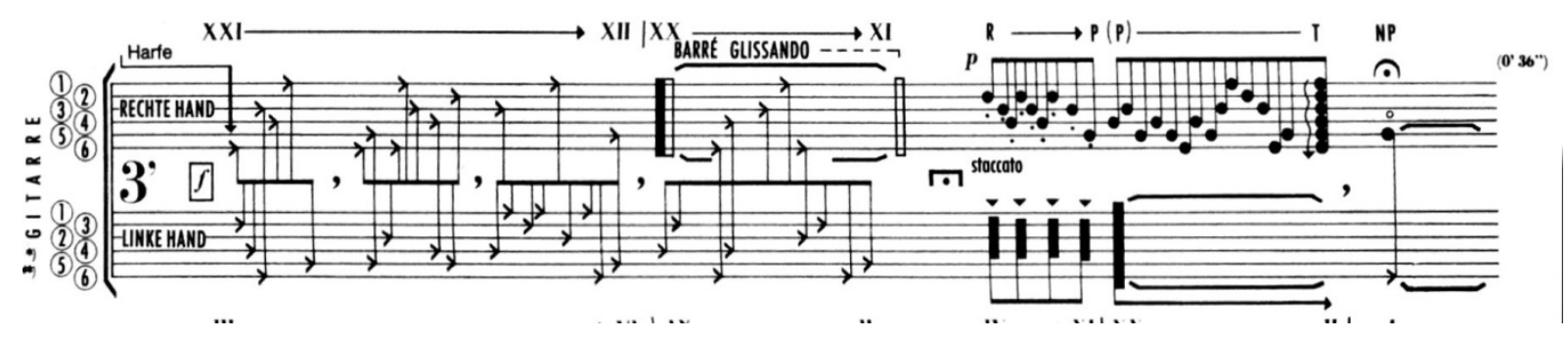

O conceito de instrumento também é estendido em Sonant: ele é, potencialmente, qualquer objeto capaz de emitir som. Ao mesmo tempo, Kagel investiga maneiras de se fazer música sem som, mas com imagens e gestos, já em Musica para la torre de 1953, o compositor criou um dispositivo de luzes que funcionava segundo um pensamento polifônico em que crescendos e diminuendos se sobrepunham de forma independente. 
(Des-)construindo o gesto do violonista em quatro obras da segunda metade do século XX Ledice Fernandes Weiss

O novo teatro musical não é uma forma a mais de teatro, distinguível por seu estilo, mas sim o uso do pensamento musical no campo teatral. A fala, a luz, o movimento se articulam nele de maneira comparável à dos sons, cores sonoras e andamentos. Trata-se, portanto, da musicalização das formas de representação e das relações entre os intérpretes. (KAGEL, 1988, p. 26).

Assim, em "Marquez le jeu (à trois)" e "Pièce touchée, pièce jouée" (partes de Sonant), a peça abre a possibilidade de uma interpretação virtual, como se lê no prefácio de cada movimento: "Aside from a real (conventional) instrumental interpretation, a 'virtual' interpretation of this section is also possible: the musicians can mimic exactly the instrumental performance of their parts, in that all the movements necessary for actually playing are imitated" (KAGEL, 1960, “Pièce touchée, pièce jouée”, contracapa).

O violonista Wilhelm Bruck comenta a parte de violão de Sonant, em que

As longas distâncias e ações diferenciadas da mão esquerda (tocando com notas em som ordinario ou em harmônicos; Glissandos; toques em staccato ou legato; ligados descendentes e ascendentes), ainda mais destacadas pela dinâmica geralmente muito piano, dão ao intérprete a impressão de que a partitura descreve a produção sonora - com a ajuda de sua altura -, e mais precisamente sua localização e seu tipo (de que resultam os sons); ele entende aqui - em ambos os sentidos da palavra a música como gestual, e testemunha o nascimento do "Teatro Instrumental" sobre as cordas do violão. Isso também abre os ouvidos do público: Você ouve o que você vê! (BRUCK, 1991, p. 131). 
(Des-)construindo o gesto do violonista em quatro obras da segunda metade do século XX Ledice Fernandes Weiss

\section{Ex. 3: Sonant, Fin II (parte de guitarra).}

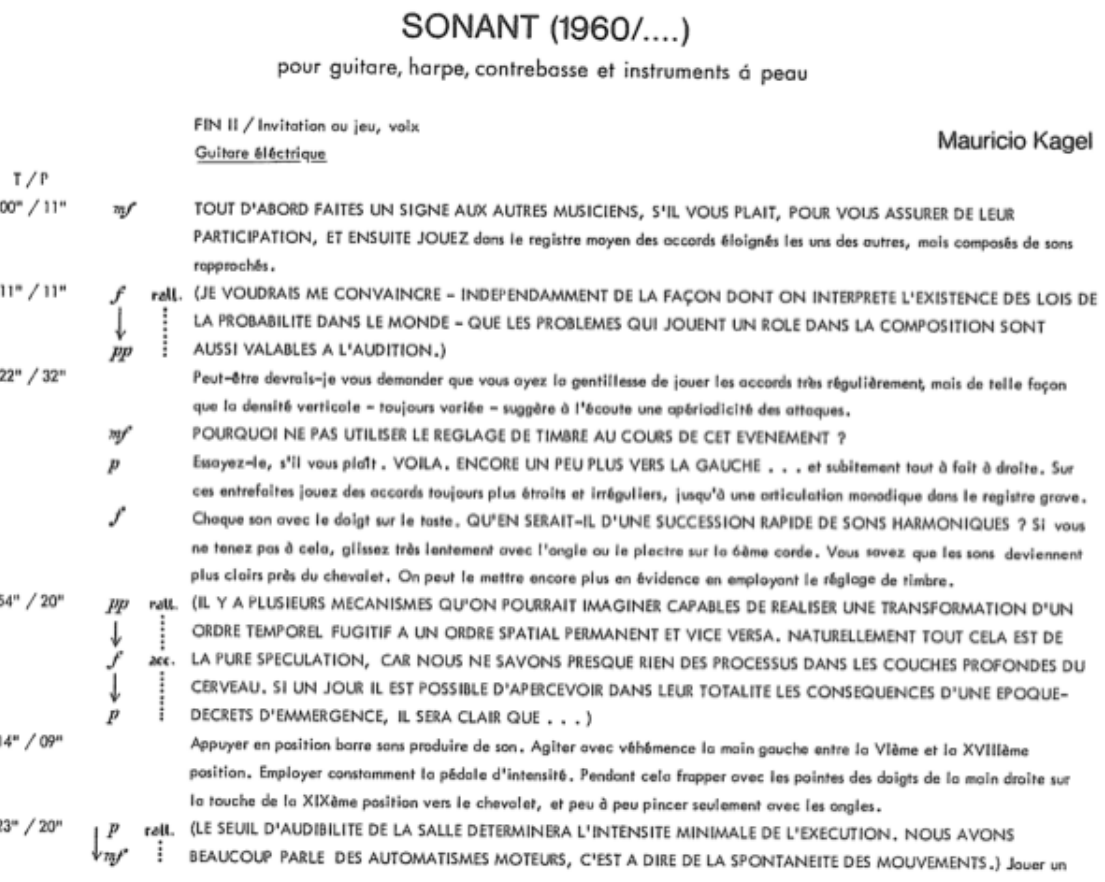

Como podemos ver no exemplo 3, Kagel cria em Fin II uma partitura verbal para cada músico. Algumas das indicações (como “apoiar a pestana sem produzir som. Agitar veementemente a mão esquerda entre as posições VI e XVIII. Empregar constantemente o pedal de intensidade. Enquanto isso, bater com as pontas dos dedos da mão direita sobre a escala, da 19a casa até o cavalete, e pouco a pouco pinçar somente com as unhas") descrevem a gestualidade instrumental de maneira lúdica. Outras propõem alguns usos inusitados do plectro, do glissando e do bottleneck, ampliando o repertório de ações instrumentais do violonista. Certas instruções, que devem ser lidas em voz alta pelo violonista, aparecem em caixa alta e entre parênteses; elas são muitas vezes indicações de performance (como "o limiar de audibilidade da sala determinará a intensidade mínima de execução") que, ao serem duplamente representadas (indicações realizadas no instrumento 
(Des-)construindo o gesto do violonista em quatro obras da segunda metade do século XX Ledice Fernandes Weiss

e lidas em voz alta ao mesmo tempo), criam um estranhamento redundante, beirando a mise en abîme, uma forma de metalinguagem. Às vezes, porém, se revestem de humor ao proporem subitamente reflexões de natureza filosófica ou relacionadas ao métier de compositor que, assim expostas fora de contexto e em caixa alta, soam surreais (como "eu gostaria de me convencer - independentemente da maneira como interpretamos a existência das leis da probabilidade no mundo - que os problemas que têm um papel na composição também são válidos na audição"). E, enfim, podem-se ver indicações que, pelo tom "ultra-polido" com o qual se dirigem ao instrumentista, instauram uma atitude humorada e teatral (como "primeiramente faça um sinal aos outros músicos, por favor, para se assegurar de sua participação" ou "Talvez eu devesse lhe pedir que tivesse a gentileza de tocar os acordes muito regularmente, mas de modo que a densidade vertical - constantemente variada - sugira à escuta uma aperiodicidade dos ataques").

Além disso, a partitura exige do violonista posturas instrumentais não convencionais, como podemos ver no exemplo 1 acima ("Instrument auf den Schoss legen", deitar o instrumento no colo). Como observamos no exemplo 3, o violonista deve usar sua voz primeiramente em uma fala neutra; mas ela também é usada em uma perspectiva mais "instrumental", fazendo sons contínuos e "ruídos vocais" indicados com precisão na partitura. O instrumentista deve ainda tocar outros instrumentos, reagir espontaneamente a estímulos dados, improvisar e dirigir seus colegas. Todas essas ações, dentro e fora de uma relação com o instrumento, contribuem para ampliar exponencialmente o espectro gestual visual e sonoro - do violonista.

Vale ainda observar uma última peculiaridade, que reforça o caráter lúdico de Sonant, os dez movimentos que compõem a partitura não precisam, pelo que é indicado, serem todos tocados, um após o outro. Se o movimento é o elemento-chave do teatro instrumental de Kagel, é porque ele lhe é fundamentalmente musical. De acordo com Barber, 
(Des-)construindo o gesto do violonista em quatro obras da segunda metade do século XX Ledice Fernandes Weiss

Apenas através do movimento se costuram a música e o teatro. Assim, em contraste com o estatismo de uma performance musical normal, o teatro instrumental musicaliza o movimento. Além disso, o movimento é um dinamizador e um deformador do som: girar, deslizar, andar, cobrir o nariz, empurrar, correr, bater ... tudo o que influencia o som dinâmica- ou ritmicamente será bem-vindo (BARBER, 1987, p. 35).

\section{V.2 Serenade (1994-1995) de Mauricio Kagel}

Serenade é uma peça para três instrumentistas (flauta, violão e percussão) que retoma, 30 anos mais tarde, princípios do teatro instrumental. Os instrumentistas devem ser bastante versáteis, capazes de tocar não só o seu instrumento principal, mas outros instrumentos da mesma família: instrumentos «baratos », brinquedos sonoros, instrumentos musicais exóticos, instrumentos preparados ou reinventados e, enfim, objetos retirados de sua utilidade habitual (como serras, por exemplo). No caso do violonista, vemos a incorporação de instrumentos associados a práticas musicais "populares", além do violão, um ukulelê, um banjo tenor e um bandolim. A gestualidade do violonista é particularmente enriquecida pela simples manipulação de quatro instrumentos e pela passagem de um instrumento a outro. Não só o momento de transição de um instrumento a outro obriga o instrumentista a uma movimentação em cena, mas a adoção de peculiaridades técnicas específicas a cada um cria uma rica variedade gestual.

Graças a essa abordagem lúdica do fazer musical, aos momentos de manipulação de objetos extra-musicais do cotidiano, às descrições verbais de ações diversas e ao jogo de sincronização que se estabelece entre os músicos, a peça se "teatraliza" cada vez mais em seu decorrer. A qualidade teatral de Serenade nasce das ações físicas que os intérpretes devem realizar: a maioria dessas ações são descritas verbalmente na partitura (Ex. 4): 
(Des-)construindo o gesto do violonista em quatro obras da segunda metade do século XX Ledice Fernandes Weiss

\section{Ex. 4: Serenade, p. 7. Descrição verbal na parte de ukulelê: o compositor pede} ao instrumentista para "congelar" o último gesto de cada motivo.

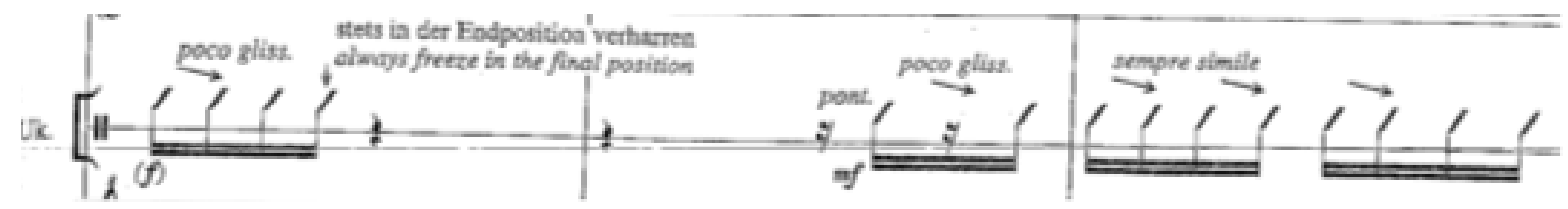

Algumas ações fazem parte do jogo instrumental ou de produção sonora e incluem:

- Ações que envolvem a manipulação de objetos que alteram a identidade sonora tradicional dos instrumentos. Assim, por exemplo, Kagel inventa uma combinação de bottleneck e palheta mole, que lhe permite criar no ukulelê uma sonoridade "infantil" e lúdica (por conseguinte, teatralizada), que sintoniza com aquela produzida por "instrumentos-brinquedos" tocados pelos outros instrumentistas, como o pequeno piano de brinquedo;

- Ações que levam à transformação de objetos do cotidiano em fonte sonora (como o papel celofane, cuja sonoridade é bastante explorada pelos três instrumentistas);

- Ações que pesquisam diferentes modos de tocar os instrumentos.

Outras ações físicas são, ao contrário, separadas da produção sonora: quase todas se concentram na manipulação do conteúdo de três sacos, no interior de cada um deles se encontram três buquês de flores. Cada saco é atribuído a um dos intérpretes. Os três grandes momentos "teatrais" de Serenade correspondem às passagens em que os três artistas, sucessiva ou simultaneamente, manipulam e "brincam" com seus três buquês de flores. Na partitura, indicam-se tais momentos pelo desenho específico de cada buquê na parte do instrumentista que realiza a cena, acrescido de uma explicação escrita. 
(Des-)construindo o gesto do violonista em quatro obras da segunda metade do século XX Ledice Fernandes Weiss

\section{5: Serenade, Prefácio: III (símbolo do do buquê de flores).}

Stielen und wenigen farblosen Blumchen.)

3. Großer BlumenstrauB, von Cellophanpapier umballe. (Ausnahme: der StrauB des Gitarristen ist unverpackt; dez des Schlagzeugers dagegen beseht aus 2 knappen Lagen Cellophanpapier und enthält ledigiich Grünzeug und einen roten, zerknüilcen Stofflappen.) of scems, and a few colourless litele flowers.)

3. A large bunch of flowers wrapped in cellophane. (Exception: rhe guitarist's bunch is unwrapped; conversely, the percussionist's consists of 2 scarce layers of cellophane, but only contains some greenery and a bundle of red, crumpled ciorb.)

Na verdade, o violonista de Serenade, como os outros dois instrumentistas, não precisa fazer distinção, digamos, entre "tocar violão" ou sentir o cheiro de uma flor; ao contrário, ele deve passar de uma ação a outra com fluidez e simplicidade. Em Serenade, como em Sonant, o gesto - tornado o foco e conteúdo do teatro - é ampliado pela alegre comunicação entre os performers, por suas movimentações cênicas, suas explorações de diferentes fontes sonoras e em sua relação lúdica com os objetos e entre eles.

\section{Salut für Caudwell (1977) de Helmut Lachenmann}

Salut für Caudwell, para dois violonistas, possui três características singulares na obra de Helmut Lachenmann como um todo, e que curiosamente constituem pontos em comum com uma imponente obra de 20 anos mais tarde, Das Mädchen mit den Schweffelhölzern, sua única ópera (LACHENMANN, 2001, p. 17-19). Essas singularidades são a temática de inspiração política, o uso do violão em seus ensembles e o fato de fazerem uso da linguagem verbal que, ademais, é decomposta e completamente triturada 5 .

Salut se baseia pois em um texto do escritor britânico marxista Christopher Caudwell (1907-1937). O texto, reescrito por Lachenmann, é fragmentado e partilhado entre os dois violonistas, que o recitam em soluços e balbuciamentos. Essa "violência" à linguagem seria, para o compositor, o reflexo de uma situação política extrema.

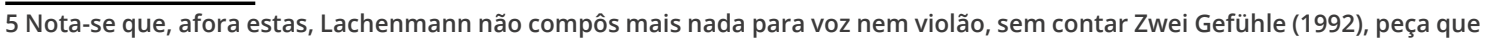
foi em seguida inserida no interior de Das Mädchen mit den Schweffelhölzern. 
(Des-)construindo o gesto do violonista em quatro obras da segunda metade do século XX Ledice Fernandes Weiss

\section{Ex. 6: Salut für Caudwell, p. 8: tratamento fragmentado do texto}

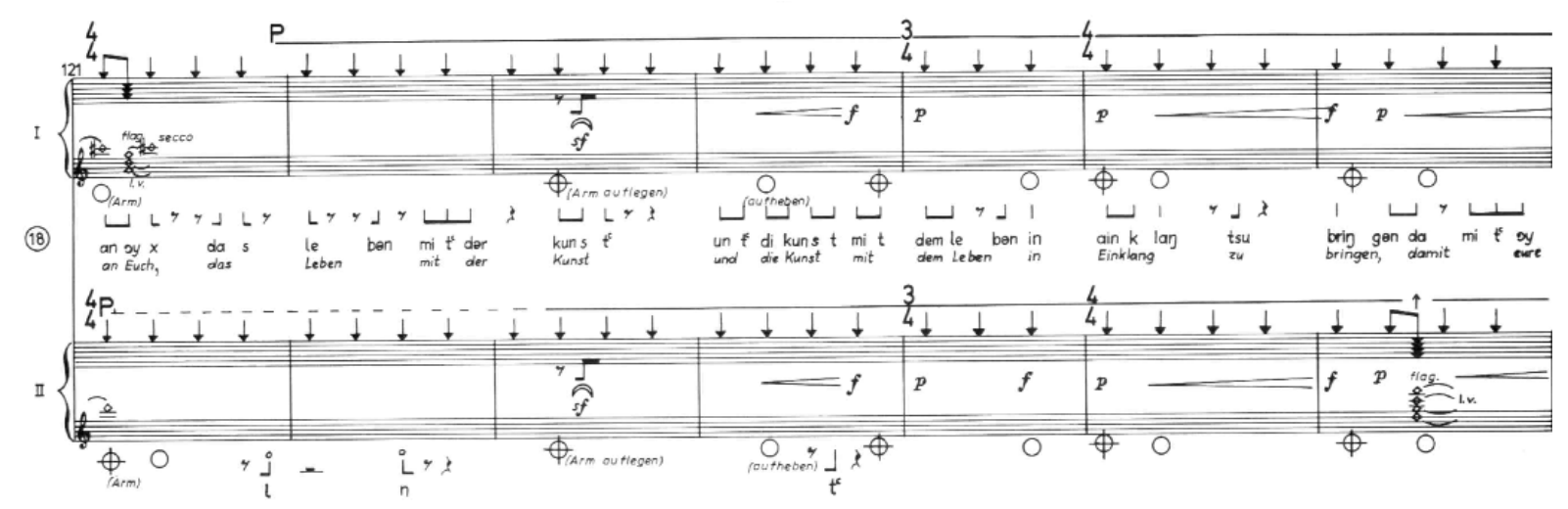

É com Salut für Caudwell que Lachenmann estabelece os alicerces da maneira como ele aborda, renova e reinventa o som e a técnica do violão. Integrando fortemente o ruído, os sons secos e abafados; sua concepção do instrumento musical é ao mesmo tempo a de um "objeto" cuja sonoridade nos informa também os materiais que o compõem. Aparecem diferentes toques no violão (pinçar, puxar, «varrer» as cordas...), que se misturam a uma grande quantidade de manipulações técnicas típicas de outros instrumentos e adaptadas, fazendo ao mesmo tempo uso de objetos e acessórios exteriores, como o bottleneck e o plectro.

Ex. 7 e Ex. 8: Salut für Caudwell, bula, p. II: uso do plectro "tamponando" sobre cordas abafadas; uso do plectro ou dedos percutindo sobre o corpo do violão.

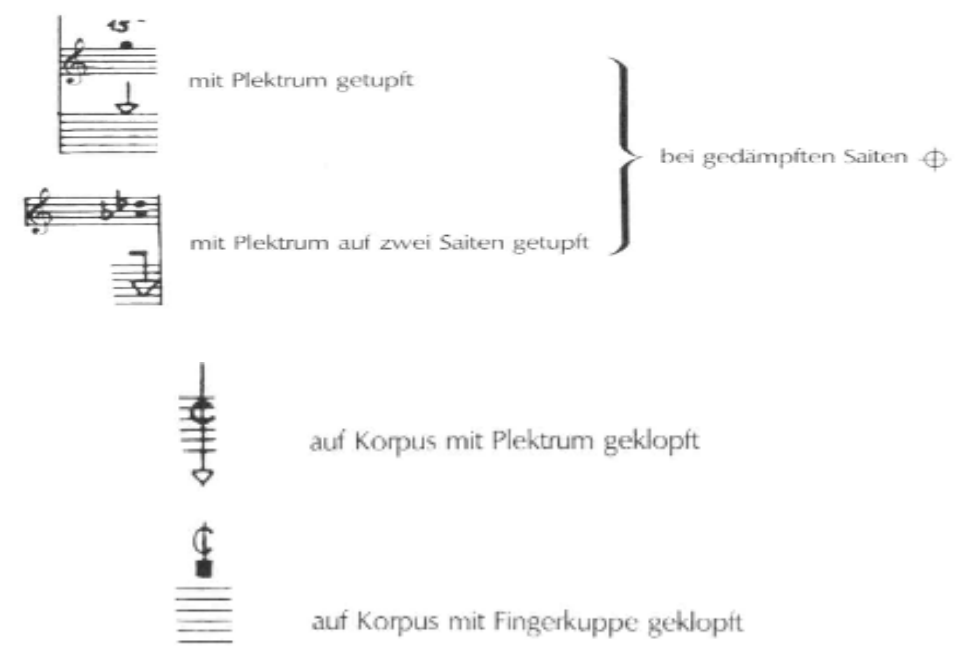


(Des-)construindo o gesto do violonista em quatro obras da segunda metade do século XX Ledice Fernandes Weiss

Lachenmann utiliza em Salut für Caudwell ações independentes entre as duas mãos, representadas por duas pautas, cada qual atribuída a uma mão (o pentagrama de cima, à direita, e o de baixo, à esquerda). Esse tipo de proposta gestual em que as mãos do violonista se emancipam uma da outra é, no background do violão, bastante inovador, ainda que particularmente aqui possa parecer comum pelo fato de também aparecer nas partituras de Sonant (Ex. 1) e de Percussion Study I (que sobrepõe um pentagrama inteiro e uma linha abaixo, ver Ex. 17).

Ex. 9: Salut für Caudwell, p. 4: notação em sistemas de duas pautas.

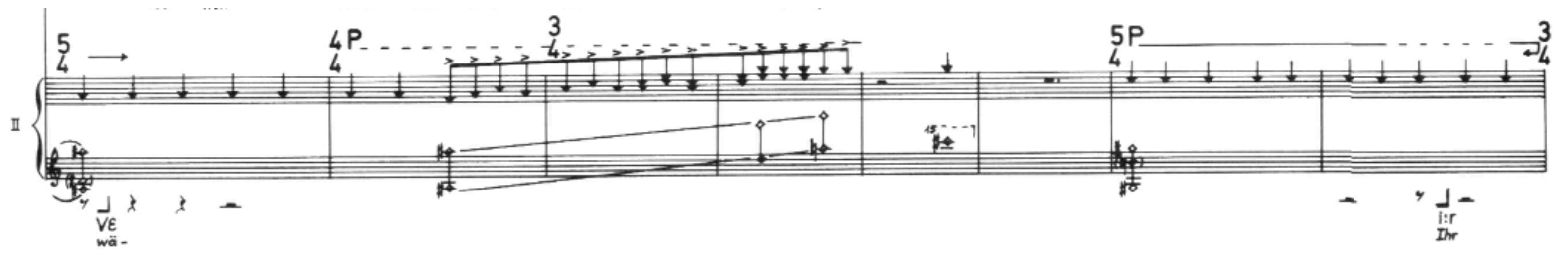

O bottleneck assume usos diferentes em Salut für Caudwell, que ampliam o espectro gestual e sonoro da obra. Ele é simbolizado na partitura por uma nota quadrada ou por um retângulo vertical para uma pestana feita por um bottleneck. Pode ser ainda usado em harmônico ou produzindo um som discreto ao ser retirado de cima das cordas:

Ex. 10: Salut für Caudwell, bula, p. II (usos do bottleneck).

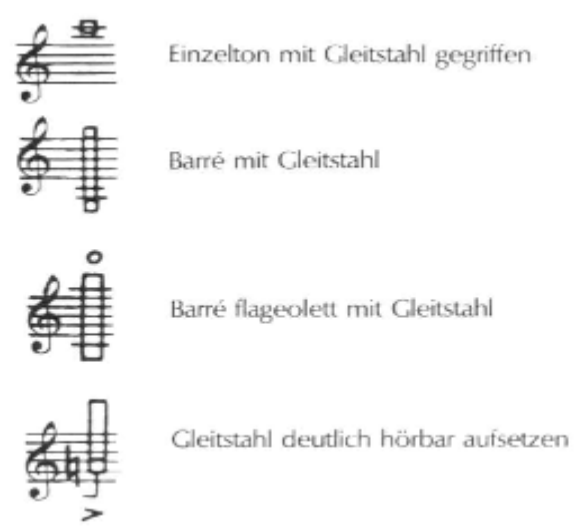

As três maneiras principais como Lachenmann emprega o bottleneck são em glissandos ascendentes ou descendentes ao longo 
(Des-)construindo o gesto do violonista em quatro obras da segunda metade do século XX Ledice Fernandes Weiss

das cordas, em percussões sobre as cordas e friccionando-o sobre as cordas, sobretudo com a mão direita. O efeito do glissando com bottleneck é anotado, como vimos no exemplo 9, sobre um sistema de duas pautas: na primeira, uma tablatura representa as cordas do violão, onde se indicam as ações da mão direita com flechas superpostas. A segunda pauta, colocada logo abaixo, indica a altura da nota mais grave de cada acorde, que situa o bottleneck na escala do violão. Esses gestos ascendentes e descendentes do bottleneck são comparados por Lachenmann ao movimento de uma serra.

O efeito de tamponamento ("getupft") é explicado na bula da partitura como uma série de percussões leves feitas com o bottleneck na mão direita sobre as cordas abafadas do violão. Tais percussões agem sobre a escala nos lugares onde as notas indicadas se encontram.

Quanto à sonoridade abafada, "erstickt", ela é uma das ferramentas favoritas da Lachenmann na exploração das possibilidades sonoras do violão. Assim, desde o primeiro compasso predomina o som abafado, que se torna a "norma" de uma música onde os sons que "vibram" são raros 6 .

Ex. 11: Salut für Caudwell, p. 10: som erstickt (o Mi agudo é uma nota abafada).

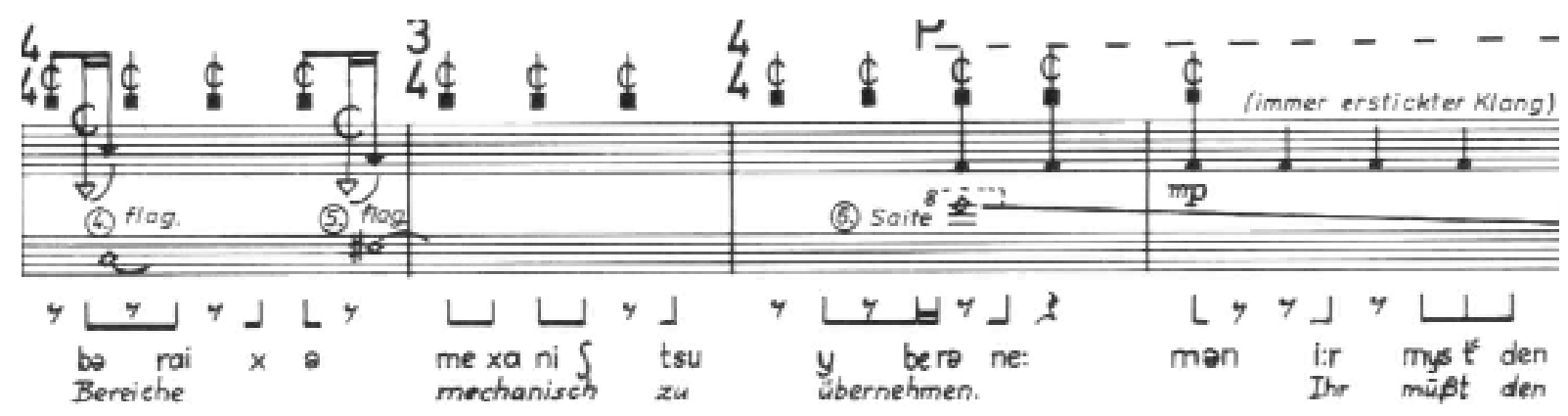

6 Os sons abafados aparecem sob diferentes formas, mas são definidos na bula como sendo o resultado de um gesto relaxado de "quase-harmônico". Seu símbolo parece de fato com o do harmônico (um losango branco), porém não seguido por um arco de ressonância. A diferença entre um e outro seria no gesto instrumental, que faz com que o dedo da mão esquerda, após encostar levemente na corda, não a libere para que ela possa ressoar: quasi Flageolett gegriffen, also lockere Saitenberührung: 'ersticktes' Klangresultat" (LACHENMANN, 1977, Prefácio). Há, também, indicações de apagamento da vibração das cordas (representado por uma semibreve com uma cruz no meio) e de deslocamento progressivo da mão direita da posição sul ponticello (ao lado do cavalete) para uma posição onde as cordas são menos tensas e permitem uma maior liberação da ressonância. 
(Des-)construindo o gesto do violonista em quatro obras da segunda metade do século XX Ledice Fernandes Weiss

Lachenmann cria sonoridades mais "ressonantes" justamente para contrastar com as "abafadas", das quais as mais emblemáticas são os harmônicos. Representados por cabeças de notas em forma de losango, seguidas de uma ligadura de ressonância, elas também compõem um efeito bastante original criado pelo compositor: o efeito «quasi Wawa», uma série de harmônicos naturais rapidamente e sucessivamente abafados e liberados ao lado do cavalete. No exemplo abaixo, o efeito (representado por círculos brancos) realizado pelo 10 violão com um bottleneck (indicado pela letra G, Gleitstahl) é sucedido pelo gesto de congelamento, starr. Ainda bastante curioso é o fato de Arthur Kampela também ter criado um efeito "Wawa" no violão a partir de uma preparação instrumental (emprego de uma colher), para sua segunda Percussion Study (ver Ex. 13). Ambos os compositores terão, cada qual com diferentes gestos, procurado recriar a sonoridade "Wawa", típica da guitarra elétrica, no violão acústico.

\section{Ex. 12: Salut für Caudwell, p. 18: Efeito "Wawa”.}

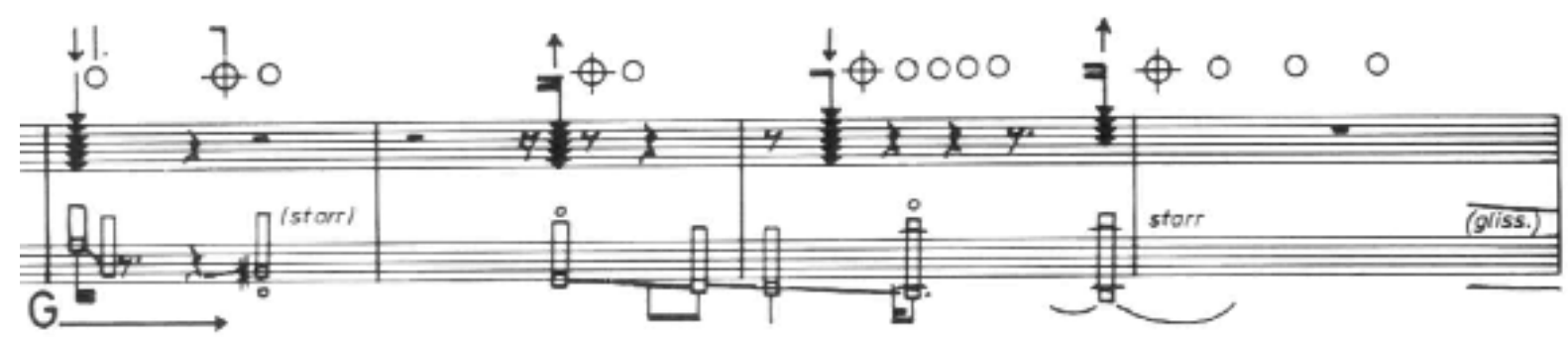

Além desses, Salut für Caudwell reinventa outros efeitos técnicos obtidos a partir de gestos instrumentais renovados: acentos, sforzatos, pizzicati-Bartok realizados com um plectro ou com unhas sobre as cordas ou sobre as partes de madeira do violão. Esses gestos visualmente enriquecidos, os sons que eles produzem e o texto pulverizado e dito em soluços pelos violonistas - semanticamente quase ininteligível - fazem nascer a mencionada teatralidade da obra, que é fundada justamente na instrumentalidade da fala e do violão. 
(Des-)construindo o gesto do violonista em quatro obras da segunda metade do século XX Ledice Fernandes Weiss

\section{Percussion Study I (1990) de Arthur Kampela}

O primeiro dos Percussion Studies de Arthur Kampela já apresenta de modo claro as principais inovações técnicas que caracterizarão esta série dedicada ao violonista que, hoje, conta com oito estudos (os últimos três semi-acabados), dos quais quatro estão devidamente publicados ${ }^{7}$ (KAMPELA, 2014; KAMPELA, 2017) e questionam as convenções técnicas e idiomáticas do instrumento. Citemos, como exemplos desse questionamento gestual, o uso do efeito "Wawa", comentado acima, em Percussion Study II (1993), ou o fato do violonista tocar, em Percussion Study 4 e 5 (2003 et 2007), uma viola de orquestra com a postura e a técnica do violão.

Ex. 13: Percussion Study II, bula: uso de uma colher ( glissando e efeito "Wawa”).

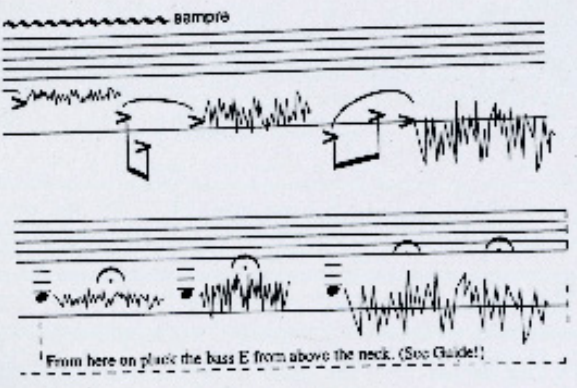

15) (Right Hand Spoon / Reverh-like or wa-wa EПTect), Tizure 15a, 15b

R.H: place the back of a spoon over the hass $\mathbf{E}$ string at the exact point of the inlersection between the string and the bridge making pressure against the bridge witile hammering (ad lib.) the bass $\mathbf{E}$ with the I eft Hand. The spoon's back should function as an axis to a tremolo-like movement where the hand twists the spoon alternately from the right to the left. The LEFT Hand plays ligado (stroke) over the $\mathbf{E}$ bass string improvising small and fast rhythmic cells. At the last note of each rhythmic cell allow a little time for the spoon (wa-wa) effect to be heard. The effect should be similar of a wa-wa pedal or an clectronic reverb.

O próprio Kampela declara em suas entrevistas (KAMPELA, s.d.) que sua concepção do som instrumental é diretamente relacionada ao corpo em movimento, ao potencial cênico da própria situação de concerto e à exploração das qualidades tácteis na relação instrumentista-instrumento.

Por entre as técnicas estendidas empregadas nos Percussion Studies, a maioria é herdada de tradições violonísticas do século XX (FERNANDES WEISS, 2019b). O que os singulariza, no entanto, é a gestualidade gerada pela combinação densa, rítmica e virtuosa

7 Os Percussion Studies 1, 2, 4 e 5 foram publicados de forma independente pelo compositor, e o primeiro deles ganhará, em meados de 2020, uma edição revista e publicada por uma editora francesa (KAMPELA, 2020). 
(Des-)construindo o gesto do violonista em quatro obras da segunda metade do século XX Ledice Fernandes Weiss

de uma grande quantidade de gestos percussivos e ações instrumentais disparates.

Ex. 14: Percussion Study 1, p. 1: encadeamento rápido e fluido dos efeitos seguintes: percussão do polegar sobre as cordas 5 e 6, ligado de mão esquerda só, percussão do polegar sobre o tampo do violão, dos dedos da mão esquerda sobre a parte inferior do tampo e Pizzicato Bartók.

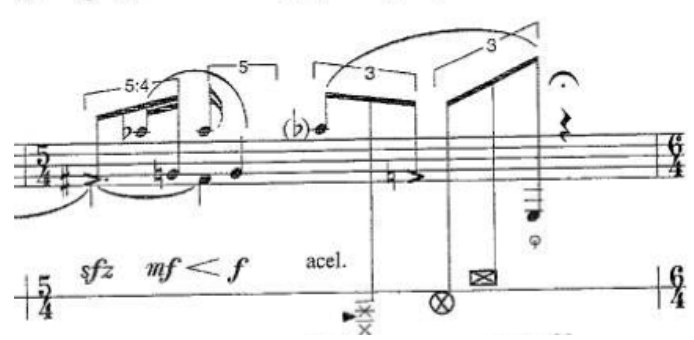

Kampela (2018) se refere a "Extend, tap, modulate" como o princípio segundo o qual des-constrói a técnica dos instrumentos. Com ele, se vale da técnica "estendida" para "ultrapassar as convenções" do instrumento, buscando outras maneiras de tocá-lo. Dentre as técnicas estendidas, suas favoritas são as que nascem da Tapping Technique, a partir da ideia de percutir, com as mãos ou com as unhas, o tampo, as demais partes de madeira e as cordas do violão; de friccioná-las e de puxá-las para fora do braço do instrumento. Aqui, também, a exploração do gesto instrumental, tanto em seu aspecto sonoro como cinético (posto que gera-se uma movimentação verdadeiramente coreográfica), se torna o centro do teatro. 
(Des-)construindo o gesto do violonista em quatro obras da segunda metade do século XX Ledice Fernandes Weiss

Ex. 15: Percussion Study 1, bula: diferentes tipos de percussões ao violão.
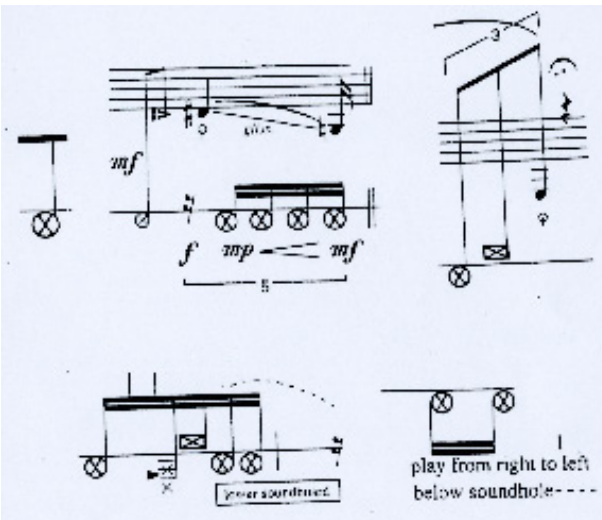

beliow soundho' -...

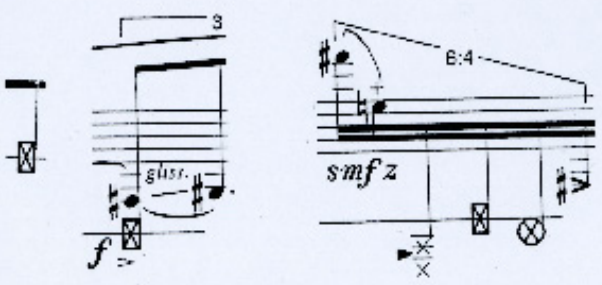

\section{1. (Right Hand Thumbj, Ligure ]}

Strike the suonulboard above the soundhole with the side (bone) of the thumb. This action should be generally done absve the soundhole. There is not a specific point in hit. just an indicated area at the upper part of the soundboard. The thumb may hit and bounce off the guitar immediatcly or stay put against the soundboard. depending on the next gesturc. Notice that this action implies an ousstretched band functioning as a countertalance for the thumb and reatly to strike the lower part of the soundboard.

\section{2. (Right Hand Thumb lower soundboard), Feure 2}

Strike the soundhoard with the thumb in its lower part. Agann, there is not a specific point in hit, just an indicated area at the lower part of the soundboard. The thumb could go either from below the soundthle towards the guitars' side or from the side towards the end of the neck, according to the next gesture.

3. (outstretched Rieht hand), Figure 3a and 3b Strike the soundboard with the right hand in its lower part, between the soundhole and bridge. Notice that ro improve the fast speed of this gesture, it is reconmended to slap the guitar using basically the $m$ and $a$ fingers of the outstretched hand (3rd and 4th fingers corunting from the thumb.) Always slap using part of the tip and the middle range of the $m$ and $a$ Fingers. (Avoid the naiis touching the board!). Bounce your hand off the guitar irromediately after hitting it. There is not a specific point to hit, just an indicated area at the luwer part of the soundboard. This action is generally done after striking the strings or tite upper soundboard with the thumb (sce figure above).

Enfim, o compositor se vale da "micro-metric modulation" para dar unidade a ritmos muito complexos que, por sua vez, permitem uma escrita baseada no ideal segundo o qual as duas mãos, e os dois braços do violonista, podem agir de modo totalmente independente um do outro, ampliando as possibilidades de movimento e de expressão corporal do instrumentista. Com isso, cresce a autonomia de cada braço, cada dedo e cada pequeno segmento da parte superior do corpo do violonista, tornando-se responsável pela execução de um gesto e som, o que faz nascer uma "coreografia" virtuosa. Como se vê no exemplo 16, essa independência entre mãos é geralmente transcrita em duas linhas, o pentagrama superior para a esquerda em ações como ligados "percutidos" ou pinçados com os dedos da mão esquerda, e a linha posicionada abaixo do pentagrama para as percussões feitas com a mão direita. 
(Des-)construindo o gesto do violonista em quatro obras da segunda metade do século XX Ledice Fernandes Weiss

Ex. 16: Percussion Study 1, p. 7: ação independente das mãos.

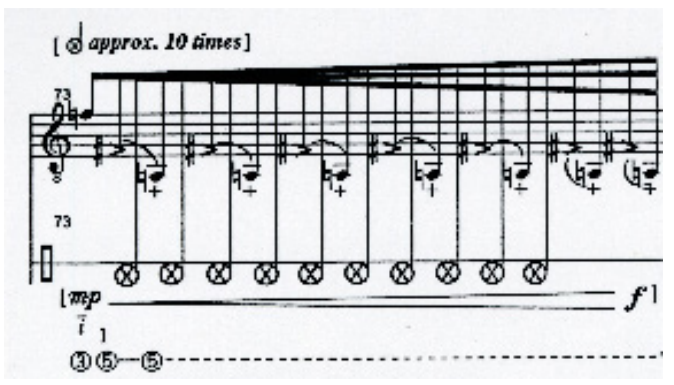

\section{Considerações finais}

Analisamos a natureza da relação entre o gesto instrumental e seu resultado sonoro, e pudemos atribuir ao gesto instrumental o status de "conteúdo", ao invés de um mero "meio técnico". O reconhecimento da importância do gesto, em detrimento de valores que antes puderam gozar de uma supremacia unívoca (como, por um lado, uma mistificada concepção artística que estaria por trás da composição, fazendo papel do "fundo" em relação à "forma", e por outro, a técnica e o virtuosismo), revela uma busca da essência da composição musical. Longe de considerarmos a tecnicidade do gesto instrumental como uma ferramenta a « se esconder nos bastidores ", fazendo um paralelo com a arte teatral, almejamos promover a própria ferramenta a elemento expressivo, a conteúdo musical.

Observa-se, nesse sentido, que a escrita musical que investigamos aqui se atém a compreender e integrar a performance segundo uma abordagem propositadamente tátil do instrumento, experimentando maneiras de extrair som dele e gozando das sensações acústicas que este the proporciona. Esse elemento sensorial, tanto em sua sugestão escrita (na forma da partitura) como na vivência do performer, é parte integrante do meio expressivo e pretende chegar ao ouvinte/espectador igualmente através de seus sentidos. Paralelamente, uma outra ferramenta recorrente de inovação das técnicas instrumentais dessas obras foi a 
(Des-)construindo o gesto do violonista em quatro obras da segunda metade do século XX Ledice Fernandes Weiss

manipulação instrumental utilizando objetos exteriores que, como os dedos do violonista, serviram para acionar as cordas e demais partes do violão visando a produzir sons.

É assim que as quatro obras que percorremos integram, a partir de diferentes recursos instrumentais, uma ampla gama de gestos e movimentos. Isso inclui, além de técnicas já conhecidas, tradicionais ou estendidas ${ }^{8}$, a invenção de sons incomuns, fruto de pesquisas pessoais de cada um.

Acrescem-se recursos extra-instrumentais: indicações cênicas na manipulação de flores, posturas instrumentais incomuns, gestos que extrapolam o instrumento e relações lúdicas entre instrumentistas são exemplos de gestos cuja musicalidade não mais é somente sonora, mas por vezes visual ou coreográfica.

Há uma vasta quantidade de perspectivas que se abrem, tanto para o compositor, para o intérprete, como para a pesquisa musicológica. Elas dizem respeito a questões como a do movimento musical induzindo os micro-movimentos corporais na interpretação instrumental (aspecto que é igualmente pertinente para um repertório musical mais tradicional); a da transcendência artística e catártica que se dá assim que se inovam possibilidades de relação entre imagem, som, texto, movimento e gesto ou, ainda, a de um ponto de vista mais fisiológico, com relação à compreensão da maneira como o instrumentista gere, em conexão, suas energias muscular, cinética e musical (a esse respeito ver Fernandes Weiss, 2020).

\section{Referências bibliográficas}

Arthur Kampela on Contact. 2005. Disponível em: https://www. youtube.com/watch? v=ROXshLJbtZO. Acesso em: 23 set. 2016.

BARBER, Llorenç. Mauricio Kagel. Madrid: Circulo de Bellas Artes, 1987. $100 \mathrm{p}$.

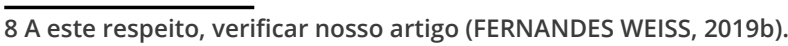


(Des-)construindo o gesto do violonista em quatro obras da segunda metade do século XX Ledice Fernandes Weiss

BRUCK, Wilhelm. !Zupfmusik!: Marginalien zu, Sonant (1960/...) für Gitarre, Harfe, Kontrabass und Fellinstrumente von Mauricio Kagel aus der Perspektive eines begeisterten Gitarristen. In: KLÜPPELHOLZ, Werner. Kagel.../1991. Cologne: DuMont Schauberg Buchverlag, 1991, p. 131.

DELUME, Caroline. À propos de Sonant (1960/...) de Mauricio Kagel . In: Les Cahiers du CIREM n. 4-5. Rouen: Publication de I'Université de Tours, 1987. p. 81-94.

DEMOZ, Heloïse. Préface. In: SCHNEBEL, Dieter. Son et corps. SaintDenis, Dijon: Labex Arts-H2H, 2017.

FERNANDES WEISS, Ledice. Corporificando a criação de sonoridades expandidas. In: CONGRESSO DA ANPPOM, XXIX, 2019a, Pelotas.

Anais do Congresso, Simpósio temático. Disponível em: http://www. anppom.com.br/congressos/index.php/29anppom/29CongrAnppom/ paper/viewFile/5992/2333.

FERNANDES WEISS, Ledice. Compreender a técnica estendida no violão: um elogio ao gesto. Opus, v. 25, n. 3, p. 224-255, set./dez. 2019b. Disponível em:http://dx.doi.org/10.20504/opus2019c2511.

FERNANDES WEISS, L. Postura e gestos do violonista: saúde, técnica e expressão. ARJ - Art Research Journal / Revista de Pesquisa em Artes, v. 7, n. 1, 31 maio 2020.

GODOY, Rolf Inge, LEMAN, Marc. Musical gestures: sound, movement, and meaning. New York, London: Routledge Taylor \& Francis Group, 2010.

GROTOWSKI, Jerzy. Em busca de um Teatro Pobre. $4^{a}$ edição. trad. Aldomar Conrado. Rio de Janeiro: Editora Civilização Brasileira, 1971. $220 \mathrm{p}$.

HEILE, Björn. The Music of Mauricio Kagel. Aldershot/Sussex: Ashgate Publishing limited, 2006. 209 p.

HILBERG, Franck. Probleme eines Komponierens mit Geräuschen. Aspekte der Materialbehandlung bei Helmut Lachenmann.

Mitteilungen der Paul-Sacher-Stiftung, Basiléia, v. 8, p. 25-30, 1995. 
(Des-)construindo o gesto do violonista em quatro obras da segunda metade do século XX Ledice Fernandes Weiss

KAGEL, Mauricio. L'œuvre cinématographique: 1965-1987. Paris:

Centre Georges Pompidou/Ircam/Goethe Institut, 1988.

KAGEL, Mauricio. Serenade. Partitura. Frankfurt: Henry Litolff's Verlag/ C.F. Peters, 1995.

KAGEL, Mauricio. Sonant. Partitura. Frankfurt: Henry Litolff's Verlag/ C.F. Peters, 1964.

KALTENECKER, Martin. Avec Helmut Lachenmann. Paris: Édition Van Dieren, 2002. 344 p.

KAMPELA, Arthur. Danças Percussivas (Percussion Study I and II). Partitura.s.l. Edição particular do compositor, 1995.

KAMPELA, Arthur. Entrevista de Fernando Cury. Violão Entre Vistas. s.I. s.n. s.d. Disponível em: https://www.youtube.om/watch?v=zNttEFBFkFY. Acesso em: 7 dez. 2015.

KAMPELA, Arthur. [Sobre casas de edição musical]. WhatsApp: 25 jun. 2020. 2 mensagens de WhatsApp..

LACHENMANN, Helmut. Salut für Caudwell für zwei Gitarristen. Partitura. Wiesbaden: Breitkopf und Härtel, 1985.

LACHENMANN, Helmut. Helmut Lachenmann. In: KALTENECKER, Martin. Avec Helmut Lachenmann. Paris : Édition Van Dieren, 2002.

RODRIGUES, M. Performance, Corpo e Ação na Composição Musical. 2012. 282 fl. Tese (Doutorado em Arte e Tecnologia da Imagem). Programa de Pós-Graduação em Artes, Universidade Federal de Minas Gerais, Belo Horizonte, 2012.SCHNEBEL, Dieter. Son et corps. SaintDenis, Dijon: Labex Arts-H2H, 2017.

STOIANOVA, Ivanka. Geste-texte-musique. Paris: Union Générale d'éditions, 1978. 